\title{
Implante Direto de Stent Coronariano: Efeitos na Resposta Inflamatória Sistêmica
}

\author{
João Paulo Zouvi ${ }^{1}$, Marco Vugman Wainstein ${ }^{1}$, Jorge Pinto Ribeiro ${ }^{1}$
}

\begin{abstract}
RESUMO
Introdução: $O$ implante direto de stent, potencialmente menos traumático do que a técnica convencional com prédilatação, por permitir simultaneamente o remodelamento da placa ateromatosa e o tratamento de eventual dissecção, resultaria em redução da resposta inflamatória sistêmica. Objetivos: Comparar as técnicas direta e convencional de implante de stent quanto aos efeitos na resposta inflamatória sistêmica. Método: Pacientes encaminhados para implante eletivo de stent coronariano foram divididos em dois grupos, direto e convencional. A resposta inflamatória sistêmica foi avaliada pela variação pré e pós-intervenção dos níveis séricos de proteína C reativa (PCR-us) e CD40L. Resultados: Foram incluídos 34 pacientes no grupo direto e 26 no grupo convencional. Os dados demográficos e angiográficos foram semelhantes entre os grupos direto e convencional, respectivamente: idade $58,0 \pm 11,6$ e $59,5 \pm 9,8 \quad(p=0,60)$; sexo masculino $67,6 \%$ e $69,2 \% \quad(p=0,99)$; diabéticos $17,7 \%$ e $26,9 \%(p=0,53)$; lesões B2/C $52,9 \%$ e $38,5 \%(p=0,31)$ e diâmetro de referência pré-intervenção $(\mathrm{mm}) 2,67 \pm 0,7$ e $2,81 \pm 0,7 \quad(p=0,45)$. Pós-intervenção para ambos os grupos houve elevação semelhante dos níveis séricos de PCR-us ( $p$ tempo $<0,001 ; p$ interação $=0,86 ; p$ grupo $=0,22$ ) e redução similar dos níveis séricos de CD40L ( $p$ tempo $=0,02 ; p$ interação=0,81; $p$ grupo=0,39). Conclusão: As técnicas direta e convencional de implante de stent coronariano foram equivalentes quanto a seus efeitos na resposta inflamatória sistêmica.
\end{abstract}

DESCRITORES: Angioplastia transluminal percutânea coronária. Proteína C-reativa. Ligante a CD40.

A técnica de implante de stent coronariano sem pré-dilatação é denominada direta; seus resultados clínicos são comparáveis aos da técnica convencional $^{1}$, com potenciais vantagens, como redução

\footnotetext{
1 Universidade Federal do Rio Grande do Sul (UFRGS) - Hospital de Clínicas de Porto Alegre (HCPA) Hospital Bruno Born

Correspondência: João Paulo Zouvi. Rua Dona Eugênia, 1206/301

- Porto Alegre - RS - Brasil - CEP 90630-150 - Tel.: (51) 9963-3684

- Fax: (51) 3581-3373 - e-mail: jpzouvi@cpovo.net

Recebido em: 13/1/2007 • Aceito em: 21/2/2007
}

SUMMARY

Direct Stenting: Effects on the Systemic Inflammatory Response

Background: Direct stenting might be less traumatic than conventional predilation stent implantation, as it simultaneously treats the lesion and seals possible artery dissection. Potentially, this could reduce the deleterious impact on the systemic inflammatory response. Objectives: To compare the effects of direct and conventional stenting techniques on systemic inflammatory response. Method: Patients referred for elective implant of coronary stenting were divided into 2 groups: direct stenting and conventional stenting. Systemic inflammatory response from all patients was evaluated through pre and post-stenting serum levels range of high-sensitivity C-reactive protein (hs-CRP) and CD40L. Results: 34 patients were included in the Direct Stenting Group, while 26 patients were treated with predilation. Demographic and angiographic data were similar between Direct and Conventional groups, respectively: age $58.0 \pm 11.6$ and $59.5 \pm 9.8(p=0.60)$; male $67.6 \%$ and $69.2 \%(p=0.99)$; diabetics $17.7 \%$ and $26.9 \%$ $(p=0.53)$; B2 or C ACC/AHA lesion type $52.9 \%$ and $38.5 \%$ $(p=0.31)$; pre-procedure reference vessel diameter $(\mathrm{mm})$ $2.67 \pm 0.7$, and $2.81 \pm 0.7 \quad(p=0.45)$. Post-intervention in both groups showed similar increase in hsCRP serum levels ( $p$ time $<0.001 ; p$ interaction $=0.86 ; p$ group $=0.22$ ) and a similar decrease in CD40L serum levels ( $p$ time $=0.02 ; p$ interaction $=0.81 ; p$ group $=0.39$ ). Conclusion: Direct and conventional stenting techniques were equivalent regarding their effects on the systemic inflammatory response.

DESCRIPTORS: Angioplasty, transluminal, percutaneous coronary. C-reactive protein. CD40 ligand.

do tempo de isquemia, custo do procedimento e menor exposição à radiação ionizante ${ }^{2}$. Sob o ponto de vista angiográfico, os estudos clínicos apontam para uma taxa de reestenose semelhante entre as técnicas direta e convencional ${ }^{3}$. O avanço tecnológico permite o emprego da técnica de implante direto de stent numa fração substancial dos pacientes submetidos a angioplastia coronariana ${ }^{4}$.

Diferentemente da convencional, a técnica direta caracteriza-se pela simultaneidade do remodelamento da placa e tratamento de eventual dissecção antes do 
restabelecimento do fluxo sangüíneo, o que minimizaria a incidência de oclusão aguda e embolização distal ${ }^{5}$. O implante de endoprótese estimula a resposta inflamatória, detectável por marcadores como a proteína C reativa ultra-sensível (PCR-us) e CD40L ${ }^{6-13}$. Potencialmente, a técnica direta seria menos traumática que a convencional, resultando em menor acometimento do fluxo coronariano, em redução da resposta inflamatória sistêmica e menor lesão miocárdica.

O presente estudo tem como objetivo principal comparar as técnicas de implante de stent, direta e convencional, quanto a seus efeitos na resposta inflamatória sistêmica.

\section{MÉTODO}

\section{População}

Realizamos um ensaio clínico randomizado, cuja amostra foi constituída por pacientes estáveis, referenciados por seus médicos assistentes para implante eletivo de stent coronariano e que, à avaliação dos operadores, poderiam ser tratados pela técnica direta ou convencional. Foram incluídos pacientes de ambos os sexos, com angina estável ou isquemia miocárdica detectável por teste funcional, com idade entre 18 e 75 anos, que concordaram em participar mediante assinatura do termo de consentimento informado. Foram considerados critérios de exclusão: contra-indicação ao emprego da técnica direta, ou seja, lesão oclusiva ou suboclusiva, com marcada calcificação ou tortuosidade proximal ou em bifurcação cujo ramo apresentasse lesão ostial; uso prévio ao procedimento de ultra-sonografia intracoronariana; situações clínicas potencialmente modificadoras de marcadores utilizados como desfecho, tais como doença do sistema conectivo, síndrome coronariana aguda, insuficiência cardíaca classe III ou IV, cirurgia de porte nos últimos três meses, infecção sistêmica, neoplasia, uso de imunossupressores ou antiinflamatórios (exceto aspirina $<0,5 \mathrm{~g} / \mathrm{dia}$ ) ou emprego de stents farmacológicos; intervenção em mais de uma lesão no mesmo procedimento; intervenção em enxerto venoso aorto-coronariano; trombo intracoronariano; lesão reestenótica; indicação de antagonistas dos receptores $2 \mathrm{~b} 3 \mathrm{a}$ e recusa ao fornecimento do termo de consentimento. $\mathrm{O}$ estudo foi aprovado pela Comissão de Ética em Pesquisa do Hospital de Clínicas de Porto Alegre e realizado no Hospital Bruno Born (RS).

\section{Protocolo do Estudo}

Os pacientes foram randomizados em dois grupos - direto e convencional - de forma não estratificada, mediante emprego de tabela de números aleatórios. Em todos os pacientes, a pré-medicação incluiu aspirina $200 \mathrm{mg}$ qd e ticlopidina $250 \mathrm{mg}$ bid ou clopidogrel $75 \mathrm{mg}$ qd, nos quatro dias anteriores e trinta dias subseqüentes ao procedimento. Pacientes não prémedicados receberam, ao menos, duas horas antes do procedimento aspirina $200 \mathrm{mg}$ e clopidogrel $300 \mathrm{mg}$. Após o posicionamento do cateter-guia, foram administradas 100 ui/kg de heparina não fracionada; doses adicionais de heparina foram suplementadas conforme o tempo de coagulação ativada, visando a mantê-lo acima de 300 segundos durante o procedimento.

As técnicas de implante de endoprótese são as padronizadas na literatura. A pré-dilatação foi realizada sistematicamente com cateter-balão de calibre dois milímetros, com extensão aquém à da lesão-alvo e expandido com baixa pressão por aproximadamente dez segundos. Os tipos de stent utilizados foram padronizados e identificados; todos eram de aço inoxidável 316 L. As dimensões dos stents foram definidas com base no método visual simples, tendo por parâmetro o calibre do cateter-guia para a estimativa da extensão da lesão obstrutiva e do diâmetro de referência coronariano; a relação de calibre balão-coronária adotada foi de 1:1. Todos os stents foram expandidos com doze ou mais atmosferas. O seguimento clínico foi de seis meses, por contato direto ou telefônico com o paciente e/ou seu médico-assistente.

Todas as imagens foram adquiridas utilizando-se o mesmo aparelho (Integris 2000 ${ }^{\circledR}$, Philips $^{\circledR}$, Holanda). As imagens foram analisadas por angiografia quantitativa (GE System ${ }^{\circledR}$, EUA), sem o conhecimento dos níveis dos marcadores inflamatórios e de mionecrose. Os seguintes parâmetros foram avaliados antes e após o implante do stent: diâmetro de referência e diâmetro luminal mínimo da coronária-alvo; extensão e grau da lesão obstrutiva.

\section{Marcadores inflamatórios e de lesão miocárdica}

As amostras para dosagem de marcadores inflamatórios PCR-us, CD40L e de lesão miocárdica CK-mb e troponina $\mathrm{T}(\mathrm{c} T \mathrm{nT})$ foram coletadas logo após a colocação do introdutor arterial e 18 a 24 horas após o procedimento. As dosagens foram feitas pela técnica de ELISA (Enzyme-Linked Immunosorbent Assay), com amostras em duplicata para o CD40L, por profissionais experientes com o método. As amostras foram centrifugadas e armazenadas $\mathrm{a}-70^{\circ} \mathrm{C}$. Após descongelamento, as amostras de plasma foram diluídas em solvente de extração (acetona, ácido hidroclórico e água) e centrifugadas. O material sobrenadante foi liofilizado em centrífuga evaporadora, durante aproximadamente 6 horas, e o ensaio realizado imediatamente após esse processo. Os reagentes foram adicionados conforme rotinas especificadas pelo fabricante (R\&D System ${ }^{\circledR}$, EUA), realizando-se após a leitura da densidade óptica (sensibilidade $<1,0 \mathrm{pg} / \mathrm{mL}$, com coeficiente de variação médio intra e interensaios de 4,2 e $5,1 \%$, respectivamente).

\section{Definições}

Sucesso angiográfico: lesão residual menor que 10\% com fluxo coronariano TIMI 3; sucesso do procedimento: sucesso angiográfico na ausência de infarto 
do miocárdio onda-Q ou não onda-Q (elevação de CK-mb acima do dobro do limite superior da normalidade), revascularização do vaso-alvo em caráter de urgência, acidente vascular encefálico, nefropatia induzida por contraste e complicações vasculares (hemorragia, oclusão arterial, pseudo-aneurisma ou fístula artériovenosa) ou óbito durante a internação.

\section{Análise Estatística}

Partindo-se de $\alpha=0,05, \beta=0,10$ (poder de 90\%) e assumindo um tamanho de efeito (E/S: effect-size) maior ou igual a 1,0 para todos os desfechos em estudo, foi estimado um tamanho de amostra mínimo de 23 pacientes por grupo (total de 46 pacientes). Os dados foram descritos por média e desvio-padrão; em presença de assimetria utilizou-se mediana e amplitude interquartil (P25-P75). Variáveis qualitativas, como sexo e fatores de risco para doença coronariana, foram descritas por freqüências absolutas e freqüências relativas e comparadas pelo teste de Qui-quadrado; quando indicado, pelo teste Exato de Fisher. Variáveis quantitativas com distribuição simétrica foram analisadas pelo teste $t$ de Student e com distribuição assimétrica pelo teste de Mann-Whitney. Para comparar variáveis quantitativas com distribuição assimétrica foi realizada sua transformação logarítmica e feita a análise de variância de dupla entrada para medidas repetidas (ANOVA). A análise dos resultados foi com base na intenção de tratamento. Foi considerado um nível de significância de 5\%.

\section{RESULTADOS}

\section{Dados Demográficos, Angiográficos e Técnicos}

O grupo direto foi composto por 36 pacientes e o grupo convencional por 24. A diferença numérica entre os grupos estabeleceu-se por dados angiográficos parciais de alguns pacientes do grupo convencional, que foram excluídos do estudo. Os dados demográficos são descritos na Tabela 1 e foram semelhantes entre os grupos direto e convencional, respectivamente: idade $58,0 \pm 11,6$ e $59,5 \pm 9,8$ ( $p=0,60)$; sexo masculino $67,6 \%$ e $69,2 \%(p=0,99)$ e diabéticos $17,7 \%$ e $26,9 \%(p=0,53)$. Os dados angiográficos são descritos na Tabela 2 e também foram equivalentes entre os grupos direto e convencional, respectivamente: artéria-alvo descendente anterior $50,0 \%$ e $42,3 \%(p=0,61)$, lesão tipo B2 ou C $52,9 \%$ e $38,5 \%(p=0,31)$, diâmetro de referência pré-

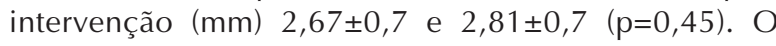
sucesso angiográfico foi de $100 \%$ em ambos os grupos e conversão de técnica ocorreu em um (2,9\%) caso, por impossibilidade de posicionamento do stent na lesão sem sua pré-dilatação.

\section{Marcadores Inflamatórios e de Lesão Miocárdica}

O comportamento dos marcadores inflamatórios foi semelhante em ambos os grupos. Os valores de PCR-us (em mg/L) antes do implante do stent, respectivamente, para os grupos direto e convencional, foram de 3,07 (1,10 a 6,61) e 3,61 (1,51 a 6,34); após o implante do stent os níveis séricos de PCR-us foram: grupo direto $5,83(2,34$ a 9,35), grupo convencional 6,90 (3,64 a 9,67) - Figura 1. A magnitude da elevação dos títulos de PCR-us foi semelhante para ambos os grupos $(p$ tempo $<0,001 ; p$ interação $=0,86$; $p$ grupo $=$ $0,22)$. Os valores de CD40L (em pg/mL) antes do implante do stent, respectivamente, para os grupos direto e convencional, foram de 4347 (2292 a 10392) e 6081 (2857 a 11466) - Figura 2. Após o implante do stent, os níveis séricos de CD40L foram: direto 3560 (1246 a 6897) e convencional 4503 (2076 a 7273), ocorrendo

TABELA 1

Dados demográficos

\begin{tabular}{|c|c|c|c|}
\hline Variável & $\begin{array}{c}\text { Convencional } \\
n=26\end{array}$ & $\begin{array}{l}\text { Direta } \\
\mathrm{n}=34\end{array}$ & $\mathbf{p}$ \\
\hline Idade, anos & $59,5 \pm 9,8$ & $58,0 \pm 11,6$ & 0,60 \\
\hline Sexo masculino, $\mathrm{n}^{\circ}(\%)$ & $18(69,2)$ & $23(67,6)$ & 0,99 \\
\hline Presença de Angina, $n^{\circ}(\%)$ & $25(96,2)$ & $28(82,4)$ & 0,13 \\
\hline Diabete, $\mathrm{n}^{\circ}(\%)$ & $7(26,9)$ & $6(17,7)$ & 0,53 \\
\hline Insulino-dependente & $3(11,5)$ & $4(11,8)$ & 0,99 \\
\hline Hipertensão, no (\%) & $22(88,0)$ & $27(79,4)$ & 0,49 \\
\hline Dislipidemia, nº (\%) & $17(65,4)$ & $22(64,7)$ & 0,99 \\
\hline História familiar, no (\%) & $5(19,2)$ & $6(17,6)$ & 0,99 \\
\hline Tabagismo, no (\%) & $11(42,3)$ & $17(50,0)$ & 0,61 \\
\hline AAS, no (\%) & $25(96,2)$ & $34(100,0)$ & 0,43 \\
\hline Tienopiridínicos, no (\%) & $26(100,0)$ & $34(100,0)$ & 0,99 \\
\hline Estatinas, $\mathrm{n}^{\circ}(\%)$ & $21(80,8)$ & $23(69,7)$ & 0,40 \\
\hline
\end{tabular}

Os dados são apresentados como média \pm DP ou contagem (porcentual). 
TABELA 2

Dados Angiográficos

\begin{tabular}{lccc}
\hline Variável & $\begin{array}{c}\text { Convencional } \\
\mathbf{n = 2 6}\end{array}$ & $\begin{array}{c}\text { Direta } \\
\mathbf{n = 3 4}\end{array}$ & $\mathbf{p}$ \\
\hline Artéria Descendente Anterior, $\mathrm{n}^{\circ}$ (\%) & $11(42,3)$ & $17(50,0)$ & 0,61 \\
Lesão tipo B2 ou C, $\mathrm{n}^{\circ}(\%)$ & $10(38,5)$ & $18(52,9)$ & 0,31 \\
Calcificação, $\mathrm{n}^{\circ}(\%)$ & $7(26,9)$ & $13(38,2)$ & 0,42 \\
Medidas pré-stent & & $2,67 \pm 0,70$ & 0,45 \\
$\quad$ Diâmetro de referência, mm & $2,81 \pm 0,68$ & $1,22 \pm 0,52$ & 0,90 \\
Diâmetro luminal mínimo, mm & $1,20 \pm 0,58$ & $54,9 \pm 14,7$ & 0,35 \\
Grau de estenose, \% & $58,7 \pm 16,3$ & $17,8 \pm 8,7$ & 0,58 \\
Extensão da lesão, mm & $19,0 \pm 6,5$ & & \\
Medidas pós-stent & & $3,12 \pm 0,68$ & 0,42 \\
$\quad$ Diâmetro de referência, mm & $2,98 \pm 0,67$ & $2,68 \pm 0,75$ & 0,10 \\
Diâmetro luminal mínimo, mm & $2,37 \pm 0,59$ & $1,22 \pm 0,90$ & 0,83 \\
Ganho agudo, mm & $1,18 \pm 0,61$ & & \\
\hline
\end{tabular}

Os dados são apresentados como média \pm DP ou contagem (porcentual).

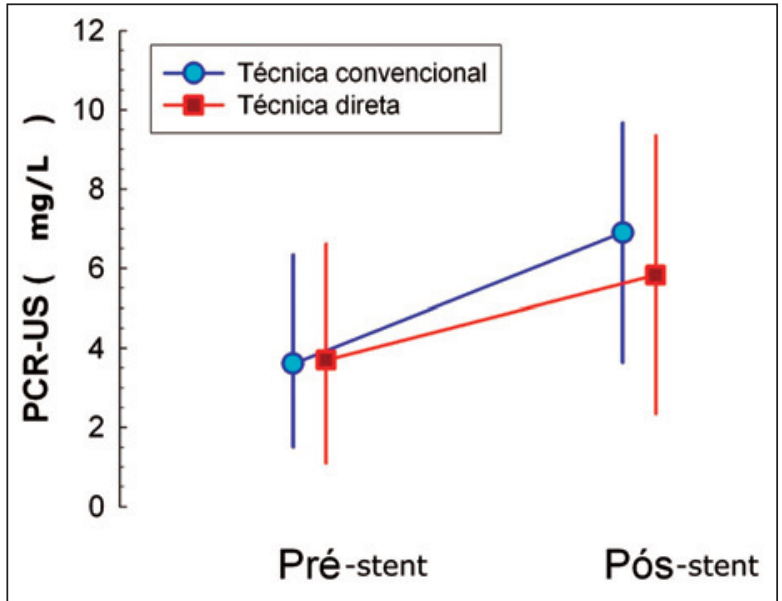

Figura 1 - Evolução da titulação da Proteína C Reativa ultrasensível (PCR-us), antes e após o implante do stent pelas técnicas convencional e direta. $\mathrm{p}$ tempo.

uma redução similar entre os dois grupos ( $p$ tempo $=0,02$; $p$ interação $=0,81 ; p$ grupo=0,39). Conforme apresentado na Figura 3, a variação da elevação dos marcadores de mionecrose foi similar para ambos os grupos, tanto para a CK-mb ( $p$ tempo $=0,001 ; p$ interação $=0,27$; $p$ grupo $=0,26)$, quanto para a troponina $T(p$ tempo $<0,001 ; p$ interação=0,20; $p$ grupo=0,07).

\section{DISCUSSÃO}

A opção pelo operador entre a técnica direta ou convencional para o tratamento de artérias coronárias nativas é subjetiva e consuetudinária. Tendo por base nossa revisão da literatura, o efeito da técnica direta de implante de stent coronariano na resposta inflama-

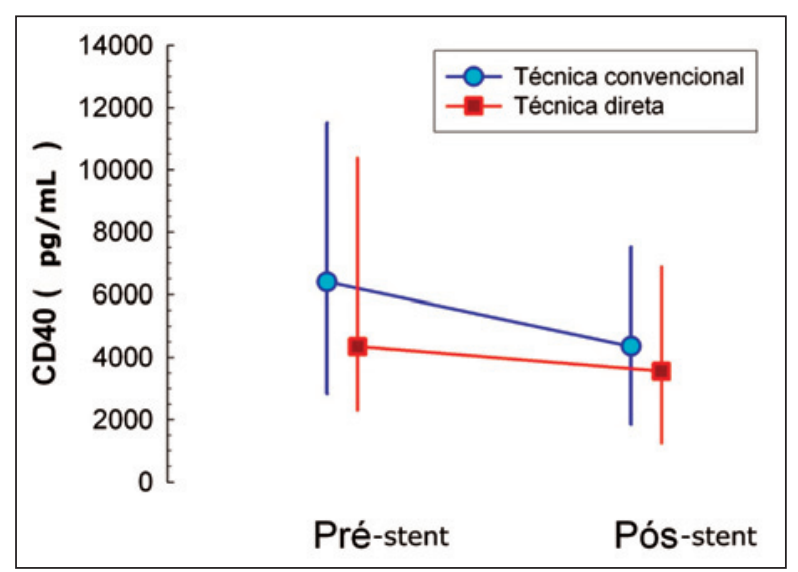

Figura 2 - Evolução da titulação do CD40, antes e após o implante do stent pelas técnicas convencional e direta, e redução similar dos níveis séricos de CD40L ( $p$ tempo $=0,02 ; p$ interação=0,81; $p$ grupo=0,39).

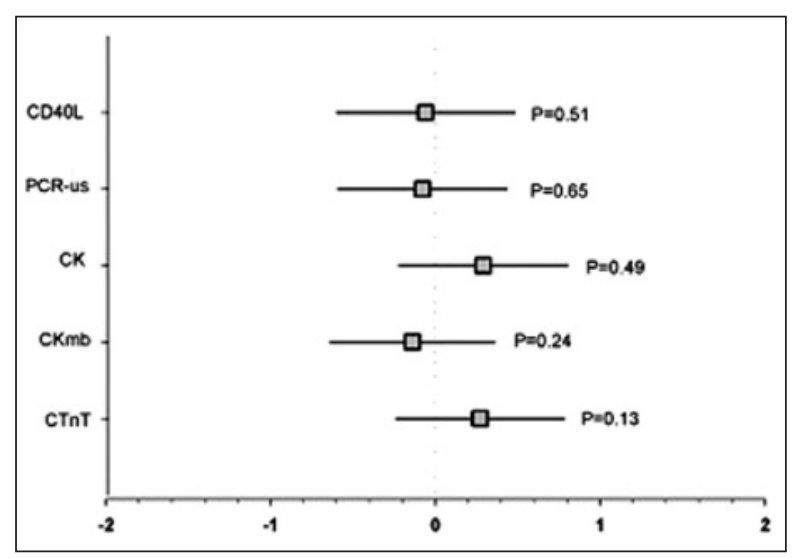

Figura 3 - Tamanho de efeito padronizado e IC 95\% da diferença entre os deltas das técnicas direta e convencional. 
tória sistêmica em pacientes estáveis permanece um tema demandante de aprofundamento.

No presente estudo, demonstramos que, comparativamente à convencional, a técnica direta não ocasionou menor estímulo à atividade inflamatória, como esperável pelo menor barotrauma infligido aos componentes da placa ateromatosa (núcleo necrótico, matriz extracelular, fibrina, cristais de colesterol) e da artériaalvo. A condição clínica de estabilidade da população estudada pode ter determinado a seleção de placas ateromatosas com acentuado conteúdo fibrótico e reduzido conteúdo lipídico, portanto, com menor potencial estimulatório de citoquinas relacionadas à atividade inflamatória. Os pacientes estariam sistemicamente menos afeitos a hiper-responsividade do sistema imunoinflamatório pela natureza estável de sua doença coronariana. No plano hipotético, se a amostra fosse constituída por pacientes com síndrome coronariana aguda, eventualmente, a resposta inflamatória à pré-dilatação poderia ser magnificada e sua repercussão aferível pela titulação dos marcadores.

A diferença de resposta à intervenção coronariana entre PCR-us e o CD40L foi chamativa e mesmo inusitada, devido à diminuição dos títulos desse após os procedimentos. No entanto, a despeito desse comportamento oposto, ambos os marcadores inflamatórios demonstraram tendência similar e constante nos grupos direto e convencional. Embora a PCR-us e o CD40L sejam ambos marcadores inflamatórios, possuem características e rotas metabólicas próprias e seu comportamento distinto já foi demonstrado anteriormente ${ }^{14}$. A elevação dos níveis de CD40L após intervenção coronariana percutânea foi demonstrada por Cipollone et al. ${ }^{15}$, porém em população com predomínio de pacientes com síndrome coronariana aguda. Desconhecemos adequada explicação para a redução dos níveis séricos do CD40L após o implante de endoprótese; no plano especulativo, eventualmente, o tratamento da placa ateromatosa pudesse minimizar junto a essa o número e a atividade de plaquetas e células endoteliais, reconhecidamente as principais fontes da síntese de $\mathrm{CD} 40 \mathrm{~L}^{16}$.

A semelhança entre as técnicas quanto à elevação de marcadores de lesão miocárdica seria atribuível à paridade dos grupos quanto à freqüência de pacientes diabéticos, presença de ramos laterais junto à lesãoalvo e à condição clínica de estabilidade dos pacientes. Na técnica direta, a seleção da dimensão do stent - extensão e calibre - é menos objetiva pela ausência do parâmetro oferecido pelo cateter-balão utilizado na pré-dilatação. A análise coronariana quantitativa pode mitigar essa limitação. Nossos resultados demonstram que não houve diferença entre os grupos quanto à necessidade de pós-dilatação, endoprótese adicional, oclusão aguda e reintervenção na lesão-alvo, situações associadas a implante de endoprótese inadequadamente dimensionada. Nesse estudo, diferentemente de outros ${ }^{17}$, a seleção de cateteres-balão com baixo perfil e exten- são e a reduzida pressão utilizada para sua expansão podem ter contribuído à redução do barotrauma inerente à pré-dilatação e, dessa forma, em seu impacto na ativação da resposta inflamatória sistêmica e na elevação dos marcadores de lesão miocárdica. Essa postulação, potencialmente explicativa da semelhança entre as técnicas, é corroborada pela ausência de dissecção angiograficamente diagnosticada nos pacientes submetidos à pré-dilatação no presente estudo, a exemplo de outros ${ }^{18}$.

São limitações do estudo sua dimensão de amostra, unicentricidade e especificidade de população. Contudo, trata-se de um trabalho representativo do cotidiano assistencial em cardiologia intervencionista e com validade externa para pacientes estáveis. Aos intervencionistas adeptos à técnica convencional, a aplicabilidade clínica desse estudo, potencialmente, estaria na sugestão de seleção de cateteres-balão para pré-dilatação subdimensionados com relação ao diâmetro arterial de referência e extensão da lesão e seu emprego a baixa pressão; essa forma de execução da pré-dilatação, além de permitir o posicionamento do stent com maior facilidade, poderia minimizar potencial efeito deletério dessa etapa na resposta inflamatória sistêmica e na liberação de marcadores de lesão miocárdica.

Em conclusão, o presente estudo demonstra a equivalência entre as técnicas direta e convencional quanto a seus efeitos imediatos na resposta inflamatória sistêmica observada no período hospitalar. Adicionalmente, confirma a semelhança entre as técnicas quanto à liberação de marcadores de lesão miocárdica.

\section{AGRADECIMENTOS}

Ao Prof. Jarbas Oliveira e Dr. Celso Bücker, pelo desprendimento demonstrado na análise dos marcadores inflamatórios. À Direção e Enfermagem da Unidade de Hemodinâmica do Hospital Bruno Born de Lajeado - RS, pelo apoio e competência essenciais à conclusão desse estudo.

\section{REFERÊNCIAS BIBLIOGRÁFICAS}

1. Brito FS Jr, Caixeta AM, Perin MA, Rati M, Arruda JA, Cantarelli $M$, et al. Comparison of direct stenting versus stenting with predilation for the treatment of selected coronary narrowings. Am J Cardiol 2002;89:115-20.

2. Martinez-Elbal L, Ruiz-Nodar JM, Zueco J, Lopez-Minguez JR, Moreu J, Calvo I, et al. Direct coronary stenting versus stenting with balloon pre-dilation: immediate and followup results of a multicentre, prospective, randomized study. The DISCO trial. Dlrect Stenting of COronary Arteries. Eur Heart J 2002;23:633-40.

3. Serruys P, Legrand V, Boekstegers $P$, et al. VELVET II direct stenting with the Bx velocity balloon-expandable stent versus predilation in an European, randomized, open label trial. Circulation 2001;104(II-622):2940.

4. Elbaz M, El Mokhatar E, Khalife K, Citron B, Izaaz K, Hamon $M$, et al. Is direct coronary stenting the best strategy for long-term outcome? Results of the multicentric randomized benefit evaluation of direct coronary stenting (BET) study. Am Heart J 2002;144:E7. 
5. Wilson SH, Berger PB, Mathew V, Bell MR, Garratt KN, Rihal CS, et al. Immediate and late outcomes after direct stent implantation without balloon predilation. J Am Coll Cardiol 2000;35:937-43.

6. Liuzzo G, Buffon A, Biasucci LM, Gallimore JR, Caligiuri G, Vitelli A, et al. Enhanced inflammatory response to coronary angioplasty in patients with severe unstable angina. Circulation 1998;98:2370-6.

7. Krüger $S$, Hoffmann $R$, Haager $P$, et al. C-reactive serum levels are elevated even at 6 months follow-up in patients with stent restenosis. J Am Coll Cardiol 2001;37(2-Suppl A):40A.

8. Chew D, Robbins $M$, Bhatt $D$, et al. CRP provides prognostic value in addition to ACC/AHA lesion score following PCI. J Am Coll Cardiol 2001;37(2-Suppl A):22A.

9. Patti G, Di Sciascio G, D’Ambrosio A, Dicuonzo G, Abbate A, Dobrina A. Inflammatory markers and coronary interventions: a potentially useful follow-up modality after stenting. Catheter Cardiovasc Interv 2002;56:341-5.

10. Buffon A, Liuzzo G, Biasucci LM, Pasqualetti P, Ramazzotti $\mathrm{V}$, Rebussi AG, et al. Preprocedural serum levels of C-reactive protein predict early complications and late restenosis after coronary angioplasty. J Am Coll Cardiol 1999;34:1512-21.

11. Varo N, Lemos JA, Libby P, Morrow DA, Murphy SA, Nuzzo R, et al. Soluble CD40L: risk prediction after acute coronary syndromes. Circulation 2003;108:1049-52.

12. Aggarwal A, Blum A, Schneider DJ, Sobel BE, Dauerman HL. Soluble CD40 ligand is an early initiator of inflammation after coronary intervention. Coron Artery Dis 2004;15:471-5.
13. Yip HK, Chang LT, Sun CK, Yang CH, Hung WC, Cheng $\mathrm{Cl}$, et al. Impact of clopidogrel on suppression of circulating levels of soluble CD40 ligand in patients with unstable angina undergoing coronary stenting. Am J Cardiol 2006; 97:192-4.

14. Tsioufis C, Dimitriadis K, Taxiarchou E, Vasiliadou C, Chartzoulakis G, Tousoulis D, et al. Diverse associations of microalbuminuria with $\mathrm{C}$-reactive protein, interleukin-18 and soluble CD40 ligand in male essential hypertensive subjects. Am J Hypertens 2006;19:462-6.

15. Cipollone F, Ferri C, Desideri G, Paloscia L, Materazzo G, Mascellanti $M$, et al. Preprocedural level of soluble CD40L is predictive of enhanced inflammatory response and restenosis after coronary angioplasty. Circulation 2003;108:2776-82.

16. Aukrust $P$, Muller $F$, Ueland $T$, Berget $T$, Aaser $E$, Brunsvig $A$, et al. Enhanced levels of soluble and membrane-bound CD40 ligand in patients with unstable angina: possible reflection of $\mathrm{T}$ lymphocyte and platelet involvement in the pathogenesis of acute coronary syndromes. Circulation 1999; 100:614-20

17. Ballarino MA, Moreyra E Jr, Damonte A, Sampaolesi A, Woodfield S, Pacheco G, et al. Multicenter randomized comparison of direct vs. conventional stenting: the DIRECTO trial. Catheter Cardiovasc Diagn 2003;58:434-4

18. Ijsselmuiden A, Laarman G, Kiemeneij F, et al. Direct stent implantation does not lead to a reduction in restenosis; a randomized controlled trial. Eur Heart J 2002;23:2407. 